\title{
CORRESPONDENCIA POÉTICA-VISUAL ENCARNADA EN DOS TIEMPOS
}

\author{
J. César Díaz Calderón \\ University of Florida \\ jdiazcalderon@ufl.edu \\ Zafo (Erick Obando) \\ Artista visual \\ ejobando23@misena.edu.co
}

\section{AGUAS AZUL OSCURO}

\section{I}

Mi árbol genealógico tiene dos generaciones y se detiene.

No puedo ir más lejos porque la mayor parte de mi historia era oral y las personas con las historias están muertas.

II

Hace un tiempo le envié un mensaje de texto a mi padre.

Le pedí las historias de sus padres.

Me dio sus nombres y sus profesiones.

Eran campesinos.

Omitió que eran dueños del terreno.

No era colectivo, eso importa en Oaxaca.

Y era buena tierra.

Lo sé porque mis medios hermanos están dispuestos a luchar por las propiedades

de mi padre.

Mi hermana y yo no pelearemos por eso.

Mi padre murió, el árbol emergente corre gran peligro.

III

Las historias fragmentadas no son infrecuentes,

ni accidentales.

¿Quiénes son los que hacen inaccesibles los archivos?

¿Fui yo por no renunciar a años de educación

para sentarme con él en la plaza para que me contara mis historias?

Siempre decía lo que pensaba cuando yo estaba presente.

¿O fue él? 
Su homofobia me hizo sacarlo de mi vida jurando que nunca volveríamos a hablar.

¿Cómo se pierden las historias?

Pregunta equivocada.

¿Por qué se pierden las historias?

¿Qué tipo de poder se crea matando gente

de cansancio?

III

En fábulas, mi madre le dice a mi hermana que las mujeres no.

Por la noche murmura los detalles de tiempos y lugares

en los que fue violada al hacerlo.

Ella me dijo una vez que estaba asustada por mí

cuando intentaba decir que estaba asustada de mí.

Recuerdo la cara de mi madre cuando le dije que podía morir pronto, porque mi investigación me está obligando a llegar a los límites de la comodidad y el poder mata lo incómodo.

Está asustada porque le puedo arrebatar a su hijo en cualquier instante.

\section{IV}

Las comidas tradicionales cuentan las historias de supervivencia en tiempos difíciles.

Usan todas las partes de los animales de maneras creativas, se adaptan a las dificultades, a la escasez y a la volatilidad de las estaciones.

Los órdenes jerárquicos alteran nuestra forma de comer, limitan nuestras herramientas de recuperación y borran las historias

que no se nos contaron.

$\mathrm{Vi}$ a mi abuela cerrar gradualmente su cocina.

Cocinar sólo para ella cuando mi familia no estaba en casa.

Mi mamá nos narró las historias de mi abuela vendiendo su comida por comida para diez. Hoy día, recuerdo pelar tamarindos en el suelo y cantar letras que he olvidado.

Cuando preparo un mole en los Estados Unidos, recito los ingredientes en voz alta, imaginando cómo fueron removidos del suelo,

cómo se secaron, se asaron y se pelaron. ¿En qué orden? ¿Cuándo?

Rueda de arriba a abajo sobre el metate.

Amor mío, rueda de abajo a arriba sobre el metate que es mi espalda.

\section{$\mathrm{V}$}

Mis rizos se entierran profundamente en mi cráneo

enredando mis pensamientos.

Desatando mi idioma.

Lenguas mágicas, bailando, engendrando silbidos, y desafiando la calma de los hábitos de saber y de no vivir lo que se sabe. 


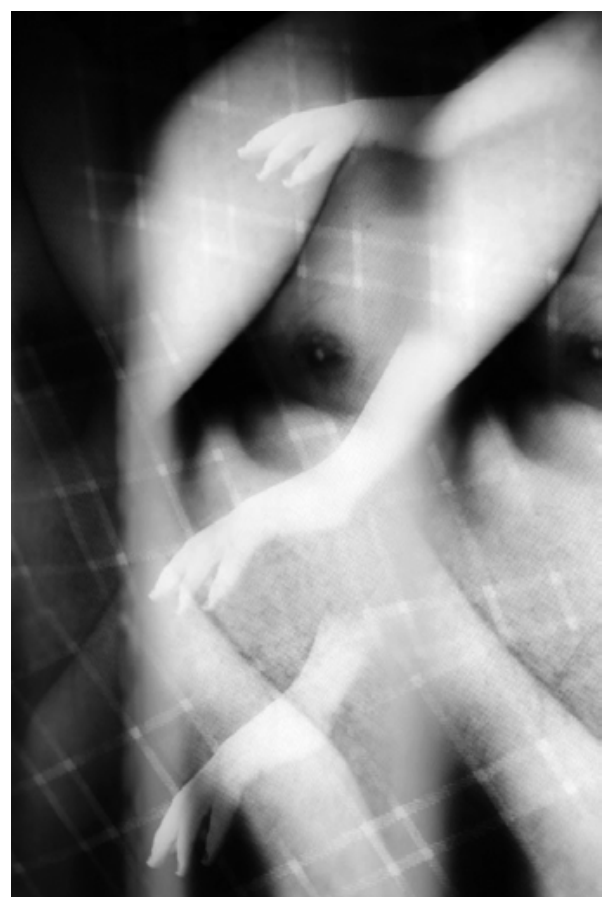

Tengo sed, sintiendo ampollas extenderse sobre mi piel dura. Mi mamá me enseñó a arrodillarme y a beber del arroyo.

Uno al lado del otro, cerdos con un poco de barro en las pezuñas y mujeres que lavan ropa que no pueden lavar en casa.

\section{VI}

¿Cómo les cuento a mis amigos esas partes de mi historia? ¿Cómo les digo mis formas de curar sabiendo que faltan algunas partes? Las razones por las que algunas nunca se encontrarán. ¿Por qué debería romper sus esperanzas con las historias de cerdos bebiendo de aguas contaminadas uno al lado del otro bajo el sol naciente?

Reconciliándome con fragmentos de historia.

Las historias se superponen, se contradicen y se interpelan.

En ocasiones también me superpongo, contradigo e interpelo.

La mayoría de las veces, floto sobre océanos azul oscuro pensando en las formas en que se mueve el agua. 


\section{LOS FREGADEROS DE LOS CUERPOS}

La ropa sucia se lava en casa y estos fregaderos ya no me alcanzan. Una al lado de la otra en la azotea alineo mis trusas blancas. Ritual colectivo de lavación de nuestras corporalidades. Las heredadas y las escogidas.

Mi mamá me enseñó a fregar. Lecciones sepultadas en práctica. Hoy me cuesta exhumar las acciones primigenias.

Este extremo sobre el otro extremo y restregar de arriba abajo sobre los montículos de cemento. La rigidez de las ondulaciones cuando rozan mis nudillos. Poco a poco te acostumbras a celebrar callosidades.

¿Cuál es el primer paso para sacar las hendiduras de mis traumas sobre los músculos que atraviesan del metatarso de mis pies a la suavidad de su entrepierna? Me creo culebra y muto pieles. Aquél brujo me dijo un día que era un acaparador porque no las abandono en la tierra. Las llevo conmigo al andar, el duelo de conocer la vida.

Lo dejé tumbado en el patio retorciéndose de dolor por el entronque. Tomé mis cosas, que son sus cosas, pero que aquél día reclamé como el precio de su ausencia. Partí y lo maté en un poema y en mis memorias. A ratos me acuerdo que tiene familia, que sus hijos lo disfrutan y que su esposa, que no es mi madre, le sirve de comer en la tarde y al anochecer. ¿Quién le da hoy el desayuno? 


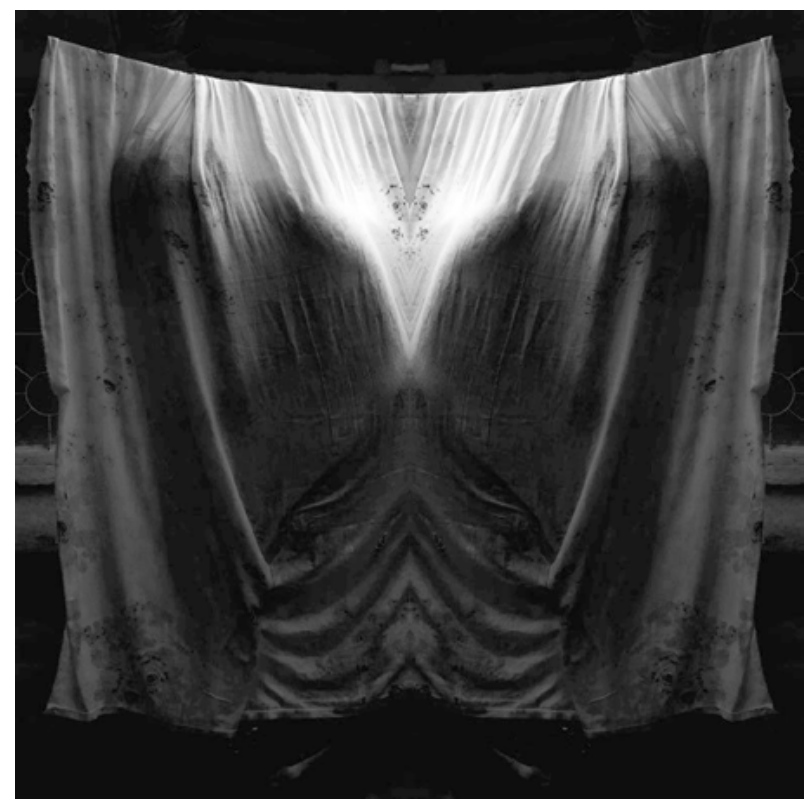

La ropa se ensucia en casa.

Se lava en sudor sobre las calles, sobre los fregaderos de los cuerpos.

Necesito bicarbonato para las manchas rojas.

Perderme en su burbujeante alivio.

Aprendí que después de un tiempo

las ropas endurecen, crujen

y se disuelven al contacto con el agua.

Voy perdiendo mis pieles,

mis pasados, mis engaños.

Me siento desnudo y mis angustias

se transmutan en sinvergüenza.

Aprendí a tejer y a escoger mis ropas.

A camuflarme y a andar sin carga.

Hace un día me aventé en la Quebrada y sentí la sal desprender mis últimas escamas.

Sigo suspendido en la profundidad del mar, ¿cómo sabré encontrar mi ascenso?

Regresaré sin pulso o me volveré pescado. 

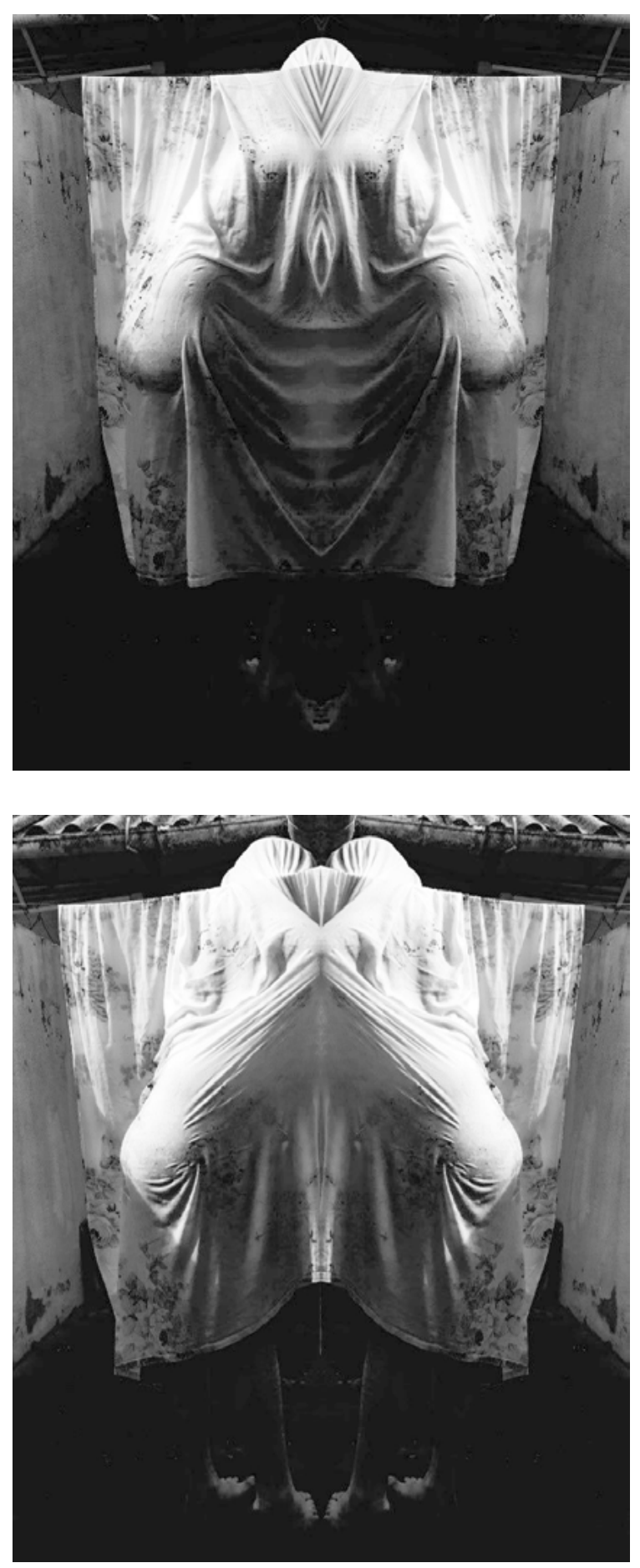